\title{
The Effect of Freezing on the Immunoprofile of Breast Carcinoma Cells
}

\author{
Asuman Argon ${ }^{1}$, Alper Şener ${ }^{2}$, Osman Zekioğlu², Murat Kapkaç³ ${ }^{3}$ Necmettin Özdemir ${ }^{2}$ \\ ${ }^{1}$ Department of Pathology, İzmir Bozyaka Training and Research Hospital, İzmir, Turkey \\ ${ }^{2}$ Department of Pathology, Ege University Faculty of Medicine, İzmir, Turkey \\ ${ }^{3}$ Department of General Surgery, Ege University Faculty of Medicine, İzmir, Turkey
}

Background: Intraoperative frozen section procedure may be required in some operations performed for breast masses.

Aims: We investigated the effect of frozen section procedure on the immunoprofile of breast carcinoma cells.

Study Design: Cross-sectional study.

Methods: A total of 53 breast carcinoma cases evaluated with intraoperative frozen sections were included in this study. Immunohistochemically, oestrogen (ER), progesterone (PR) and HER2 primary antibodies were evaluated in both frozen and non-frozen sections of each tumour sample.

Results: No difference was found between the frozen and non-frozen sections in 33 cases in terms of staining rate and intensity of ER, PR and HER2. A decrease was found in the ER, PR and HER2 stain- ing rate (in 10 cases, 9 cases and 6 cases, respectively). Likewise, a decrease was detected in ER, PR and HER2 staining intensity in 6 patients for each. Although there was no staining in frozen sections, immunopositivity was observed in 3 non-frozen sections for ER, in 2 for PR and in 5 for HER2. Statistically, a significant difference was found between the frozen and non-frozen sections in terms of staining rate and intensity for each of the three markers.

Conclusion: In this study, the frozen section procedure in breast carcinoma had a negative effect on the immunoprofile. However, considering the importance of hormone receptor status in the treatment, these results should be supported with larger series.

Key Words: Breast carcinoma, frozen examination, HER2, immunohistochemistry, oestrogen, progesterone
Breast cancer is the most common cancer in women (1). Therapeutic developments and advances in public health services increasing awareness regarding early diagnosis are rapidly progressing. Although surgery is the primary treatment in early stage breast cancers, neoadjuvant and adjuvant treatments are also important for local advanced and metastatic patients (2). Chemotherapy and radiotherapy protocols continue to play a primary role in the current conventional treatment scheme. Hormonal and targeted therapies have also been introduced into the treatment plan in recent years $(3,4)$. With those developments, pathologists have started to play a greater role in the detection of those markers that guide the treatment of breast cancer.

Intraoperative frozen section procedure may be required in breast cancer for reasons such as histological diagnosis, the presence of surgical margin positivity and lymph nodes metastasis. Morphological changes related to freezing can be ob- served in tissues undergoing routine processing after a frozen section procedure. However, the effect of the frozen section procedure on the immunoprofile of cells is still a subject of interest. This issue becomes more important in breast carcinomas because immunohistochemical (IHC) analysis guides the treatment. We investigated the effect of frozen section procedure on the oestrogen (ER), progesterone (PR) and HER2 expression in breast carcinoma cells using immunohistochemical methods.

\section{MATERIAL AND METHODS}

\section{Study population, and frozen and routine tissue processing}

A total of 53 cases evaluated with intraoperative frozen sections in our hospital between October 2009 and July 2010 were

This study was presented as a poster at the $20^{\text {th }}$ National Pathology Congress, 29 Sempteber - 3 October 2010, Eskişehir, Turkey.

Address for Correspondence: Dr. Asuman Argon, Department of Pathology, İzmir Bozyaka Training and Research Hospital, İzmir, Turkey

Phone: +90 2322505050 e-mail: asumanargon@gmail.com

Received: 02.06.2014 Accepted: 31.08.2014 • DOI: 10.5152/balkanmedj.2014.14389

Available at www.balkanmedicaljournal.org 
prospectively included in the study. A sample removed from tumours sent for intraoperative examination was frozen at $-25^{\circ} \mathrm{C}$ with polyvinyl alcohol and polyethylene glycol. After the samples evaluated through frozen section were thawed at room temperature, they were fixed in $10 \%$ formalin. The routine tissue processing was performed for the frozen and non-frozen sections and they were all embedded in paraffin blocks. Both the frozen and non-frozen sections of each tumour were placed on the same slide. The slides were prepared with five-micronthick tumour tissue. All of the haematoxylin and eosin-stained sections were examined under a light microscope. The samples where the frozen section was analysed before routine tissue processing were classified as the 1st Group. The samples that did not have the frozen section evaluated before routine tissue processing were characterised as the 2nd Group.

\section{Immunohistochemistry}

Oestrogen (Thermo, Clone: SP1, 1/400 dilution, Fremont, USA), PR (Dako, Clone: PgR636, 1/150 dilution, Glostrup, Denmark) and c-erB-2 (Dako, Polyclonal, 1/300 dilution, Glostrup, Denmark) primary antibodies were used. A fully automatic immunohistochemical staining device (Ventana BenchMark XT, Ventana Medical Systems, Tucson, USA) containing Biotin-free, HRP multimer-based, hydrogen peroxide substrate and 3, 3'-diaminobenzidine tetrahydrochloride (DAB) chromogen (ultraView TM Universal DAB Detection Kit, Catalog number 760-500, Ventana Medical Systems, Tucson, USA) was used as the immunohistochemical staining system. Tissue sections were placed on electrostatically charged slides (X-traTM, Surgipath Medical Industries, Richmond, Illinois, USA), and dried at $60^{\circ} \mathrm{C}$ for at least two hours, followed by the complete IHC staining process, including deparafinisation and antigen releasing processing in the staining device. Only the primary antibodies were manually placed as drops and incubated at $37^{\circ} \mathrm{C}$ for 30 minutes. All of the slides were evaluated by two pathologists, at least one of whom was experienced in breast pathology. At least 10 high power fields were examined in each tumour section. The rate and intensity of nuclear staining were calculated for ER and PR receptors and complete membranous staining was calculated for c-erbB-2.

\section{Statistical analysis}

The statistical analyses were performed with the SPSS software version 19.0 (IBM, New York, USA). The statistical analyses were performed with the statistical package program. The Wilcoxon analysis was used and a $p$ value $\leq 0.05$ was considered significant.
This study followed the Declaration of Helsinki on medical protocol and ethics and the regional Ethical Review Board approved the study.

\section{RESULTS}

All cases were female and the mean age was 55.26 \pm 11.69 (32-81) years. In $33(62.26 \%)$ cases, staining rate and intensity of ER, PR and HER2 were the same for the two groups.

The mean ER staining rate was $56.60 \pm 39.56 \%$ and $47.08 \pm 40.25 \%$ in the first and second groups, respectively. The rate was lower in 10 cases and higher in 1 case in the 1 st group compared to the 2nd group; the difference between the groups in terms of staining rate was statistically significant $(\mathrm{p}=0.004)$. ER staining intensity was the same in both groups in 46 cases, lower in 6 cases and higher in 1 case in the 1st group. However, the difference between the groups was not statistically significant ( $\mathrm{p}>0.05)$.

The mean PR staining rate was $24.06 \pm 31.92 \%$ and $18.21 \pm 26.51 \%$ in the first and second groups, respectively. The rate was lower in 9 cases in the 1st group compared to the 2nd group. The tumour showing a decrease in PR expression in the frozen section is shown in Figures 1, 2. PR staining intensity was the same in both groups in 47 cases and lower in 6 patients in the 1st group. The difference between the groups for both PR staining rate and staining intensity was statistically significant ( $\mathrm{p}=0.007$ and $\mathrm{p}=0.024$, respectively).

The mean HER2 staining rate was $17.36 \pm 30.51 \%$ and $12.26 \pm 27.36 \%$ in the 1 st and 2 nd groups, respectively. The staining rate was lower in 6 cases in the 1st group. The tumour showing a loss of HER2 expression in the frozen section is shown in Figures 3, 4. HER2 staining intensity was the same in both groups in 47 cases and lower in 6 cases in the 1st group. The difference between the groups for both staining rate and staining intensity was statistically significant ( $\mathrm{p}=0.027$ and $\mathrm{p}=0.020$, respectively).

Although various staining rates and intensities were observed in non-frozen sections for ER staining in $3(5.66 \%)$ cases, PR in $2(3.77 \%)$ cases and HER2 in $5(9.43 \%)$ cases, no staining was observed in the corresponding frozen sections. No ER staining was observed in the non-frozen section in one case $(1.88 \%)$ which indicated expression in the frozen section. The staining rate and intensity of each of the three markers are presented in Tables 1, 2.

\section{DISCUSSION}

Automated staining devices, highly sensitive antibody clones, imaging tests and FDA (U.S. Food and Drug Administration)- 


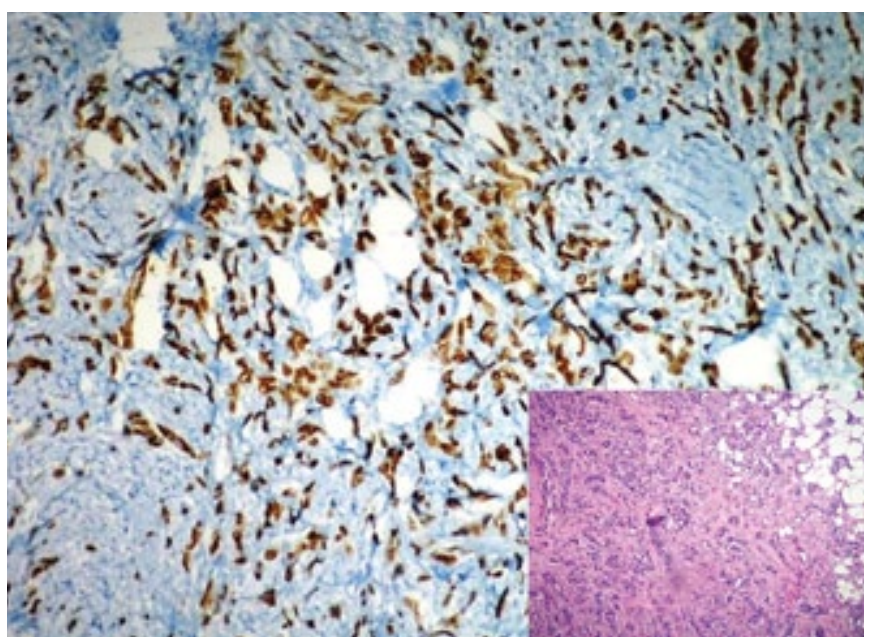

FIG. 1. Immunohistochemical PR expression (x20 magnification) in the non-frozen section of case no. 32. The histomorphological appearance is on the bottom right (Haematoxylin Eosin, x10 magnification)

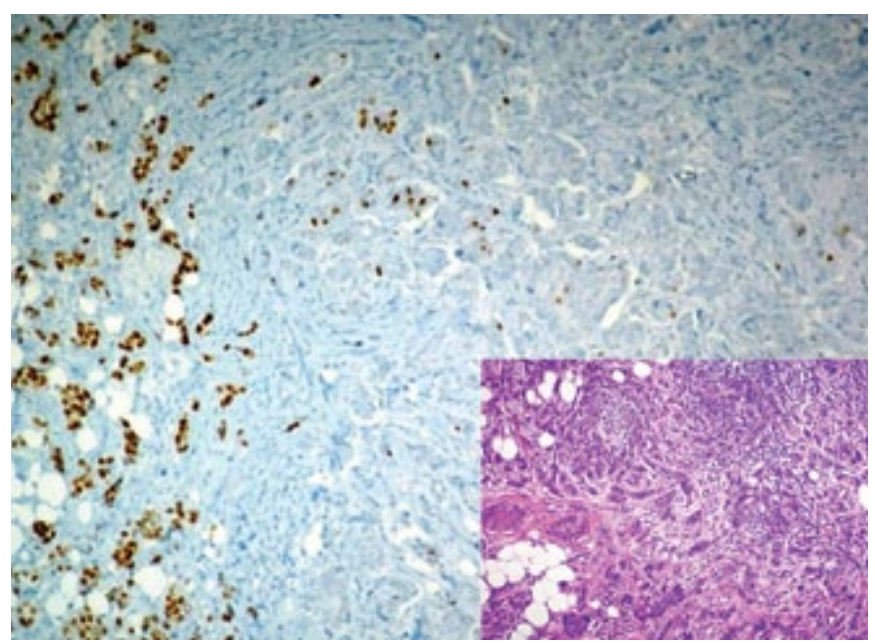

FIG. 2. Decreased immunohistochemical PR expression (x20 magnification) in the frozen section of case no. 32. The histomorphological appearance is on the bottom right (Haematoxylin Eosin, x10 magnification)

approved test kits are currently used as IHC methods in many large centres (5). However, in some pathology laboratories, there are still some problems such as inappropriate fixation, non-optimised methods for obtaining antigens and failure to establish a standard for evaluation (6-8). As known, the falsenegative evaluation of hormone receptors in breast carcinomas might lead to the patient not receiving the proper treatment option. Conversely, false-positive results can result in unnecessary treatment complications and increased cost. Tumour tissue selection, the thickness of the section, the antigen release method, the antibody choice and evaluation as well as regular verification of laboratory tests are very important in order to

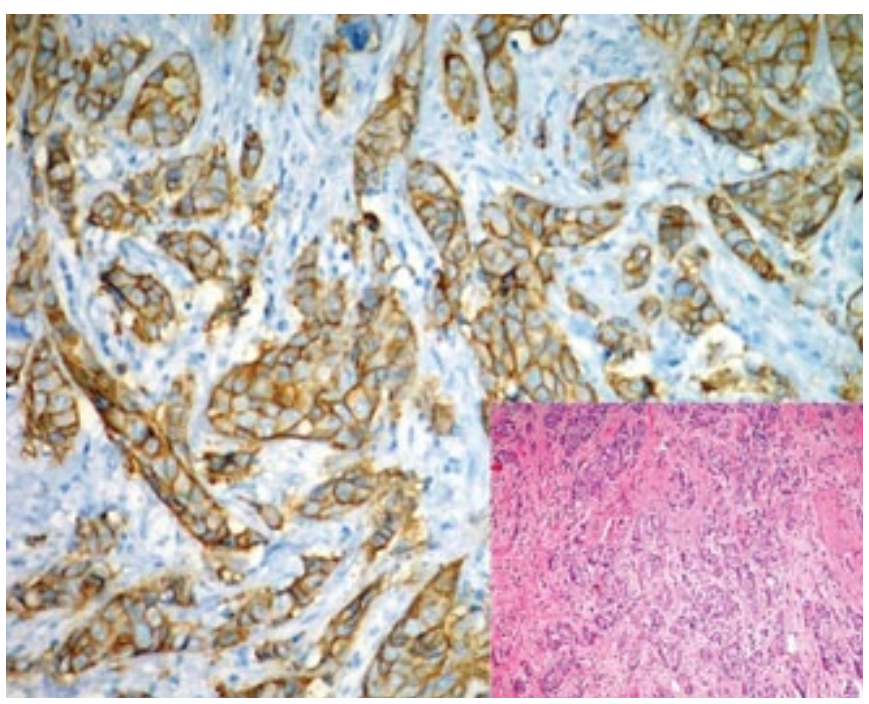

FIG. 3. Immunohistochemical HER2 expression (x40 magnification) in the non-frozen section of case no. 30. The histomorphological appearance is on the bottom right (Haematoxylin Eosin, x10 magnification)

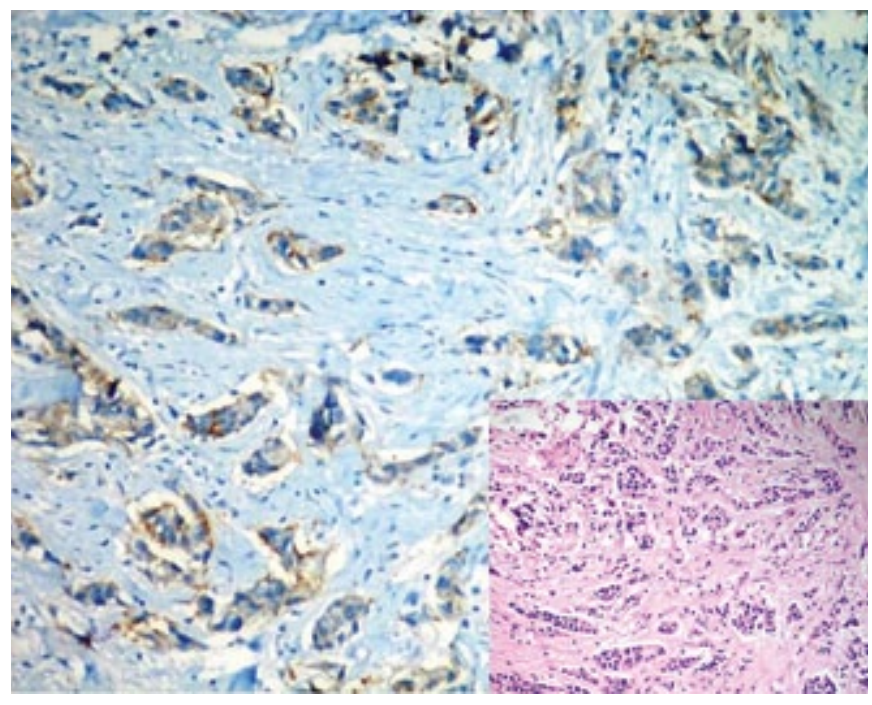

FIG. 4. Loss of immunohistochemical HER2 expression (x40 magnification) in the frozen section of case no. 30. The histomorphological appearance is on the bottom right (Haematoxylin Eosin, x10 magnification)

achieve the best results on the IHC evaluation (5, 9-11). Studies of the factors affecting IHC evaluation in breast cancers have focused on the duration of cold ischaemia, the type of fixative, fixative volume and the fixation duration $(10,12,13)$. Prolonged ischaemia is known to decrease ER and PR expression. Khoury et al. (14) reported that breast specimens should be placed in fixation solution for 1 hour and that expression loss starts in the first hour for ER and the second hour for PR. A cold ischaemia duration of 8 hours is reported to result in the 
TABLE 1. The distribution of cases according to the staining rates of the immunohistochemical markers

\begin{tabular}{|c|c|c|c|c|c|c|c|c|c|}
\hline & \multicolumn{3}{|c|}{ Oestrogen } & \multicolumn{3}{|c|}{ Progesterone } & \multicolumn{3}{|c|}{ HER2 } \\
\hline & $1 \mathrm{gr}=2 \mathrm{gr}$ & $1 \mathrm{gr}>2 \mathrm{gr}$ & $1 \mathrm{gr}<2 \mathrm{gr}$ & $1 \mathrm{gr}=2 \mathrm{gr}$ & $1 \mathrm{gr}>2 \mathrm{gr}$ & $1 \mathrm{gr}<2 \mathrm{gr}$ & $1 \mathrm{gr}=2 \mathrm{gr}$ & $1 \mathrm{gr}>2 \mathrm{gr}$ & $1 \mathrm{gr}<2 \mathrm{gr}$ \\
\hline \multirow[t]{2}{*}{ Number of cases } & 42 & 1 & 10 & 44 & 0 & 9 & 47 & 0 & 6 \\
\hline & \multicolumn{3}{|c|}{$\mathrm{p}=0.004$} & \multicolumn{3}{|c|}{$\mathrm{p}=0.007$} & \multicolumn{3}{|c|}{$\mathrm{p}=0.027$} \\
\hline
\end{tabular}

$1 \mathrm{gr}=2 \mathrm{gr}$ : Cases whose staining ratio in the tumor is equal in both groups

$1 \mathrm{gr}>2 \mathrm{gr}$ : Cases whose staining ratio in frozen section is higher than non-frozen section

$1 \mathrm{gr}<2 \mathrm{gr}$ : Cases whose staining ratio in frozen section is lower than non-frozen section

TABLE 2. The distribution of the cases according to the staining intensity of the immunohistochemical markers

\begin{tabular}{|c|c|c|c|c|c|c|c|c|c|}
\hline & \multicolumn{3}{|c|}{ Oestrogen } & \multicolumn{3}{|c|}{ Progesterone } & \multicolumn{3}{|c|}{ HER2 } \\
\hline \multirow{3}{*}{ Number of cases } & $1 \mathrm{gr}=2 \mathrm{gr}$ & $1 \mathrm{gr}>2 \mathrm{gr}$ & $1 \mathrm{gr}<2 \mathrm{gr}$ & $1 \mathrm{gr}=2 \mathrm{gr}$ & $1 \mathrm{gr}>2 \mathrm{gr}$ & $1 \mathrm{gr}<2 \mathrm{gr}$ & $1 \mathrm{gr}=2 \mathrm{gr}$ & $1 \mathrm{gr}>2 \mathrm{gr}$ & $1 \mathrm{gr}<2 \mathrm{gr}$ \\
\hline & 46 & 1 & 6 & 47 & 0 & 6 & 47 & 0 & 6 \\
\hline & \multicolumn{3}{|c|}{$\mathrm{p}=0.059$} & \multicolumn{3}{|c|}{$\mathrm{p}=0.024$} & \multicolumn{3}{|c|}{$\mathrm{p}=0.020$} \\
\hline
\end{tabular}

$1 \mathrm{gr}=2$ gr: Cases with equal tumor staining intensity in both groups

$1 \mathrm{gr}>2$ gr: Cases with higher frozen section staining intensity than non-frozen section

$1 \mathrm{gr}<2 \mathrm{gr}$ : Cases with higher non-frozen section staining intensity than frozen section

complete loss of ER expression, even when the tissue is kept at $4{ }^{\circ} \mathrm{C}$. Apple et al. (3) concluded that ER and PR expression were not affected by solution type in their study including $10 \%$ formalin, Pen-Fix, Bouin solution, Sakura Molecular fixative, zinc formalin and $15 \%$ formaldehyde. Today, the common view is that breast specimens should be fixed with $10 \%$ formalin. Although there are various recommendations for formalin fixation duration according to the size of the material (Tru-cut biopsy, partial or total mastectomy etc.), it is commonly believed that fixation for 8-36 hours is required to obtain the best immunohistochemical results (15-18). As is already known, loss of immunoreactivity can be seen after "coagulant" fixatives like acetone and ethanol are used $(19,20)$. The mechanism of tissue fixation is not well understood, but it is stated that coagulating fixatives lead to dehydration, which decomposes the protein structure by removing free water from the tissue. This situation results in denaturation and a loss of function (21). In our study, polyvinyl alcohol and polyethylene glycol were used before frozen-section. After frozen-section examination, we obtained 5-micron-thick sections from those tumours that were fixated for at least 8 hours with $10 \%$ formalin in our study. We ensured a consistent evaluation by using standards that are commonly accepted worldwide including an automated staining device, sensitive antibody clones, and FDA-approved test kits. We therefore ensured standardisation for all stages except the freezing of tumours before routine tissue processing. Those studies regarding the effect of freezing on immunoexpression often focus on cryopreservation $(22,23)$. However, in these studies, tumour tissue frozen in liquid nitrogen and stored at very low temperatures was used. We could not identify any studies about the effect of freezing at higher temperatures on immunoexpression in the literature in English. In our study, the observation of a significant difference between groups in terms of staining for each marker suggests that the frozen examination affects the immunoprofile. As is already known, artefacts may make histological evaluation difficult due to freezing in many tissues. In this study, we observed the negative effect of freezing on histomorphological features and also clearly demonstrated a negative effect of freezing on the immunoprofile. This may have resulted from damage to the protein structure due to the fixatives used or the unknown mechanism of freezing. As the number of cases was not sufficient, we were unable to comment on whether immunoprofile was affected depending on the tumour subgroups. However, the effect of frozen examination on the immunoprofile can be evaluated in detail with studies performed on large series which take the histological subgroups of the tumour into account.

Our study results indicate the negative effect of a frozen examination on hormone receptors and HER2 expression. This result should be taken into account when a frozen examination is required for incisional biopsy or tru-cut biopsy material belonging to patients who are to undergo neoadjuvant treatment or patients with very small tumours.

Ethics Committee Approval: Ethics committee approval was received for this study.

Informed Consent: Written informed consent was obtained from patients who participated in this study.

Peer-review: Externally peer-reviewed.

Author contributions: Concept - A.A., O.Z., N.Ö.; Design - A.A., A.Ş., O.Z., M.K., N.Ö.; Supervision - O.Z., M.K., N.Ö.; Resource - A.A., O.Z., N.Ö.; Materials - M.K., O.Z., N.Ö.; Data Collection\&/or Processing - A.A., O.Z., A.Ş.; Analysis\&/or Interpretation - A.A., O.Z.; Literature Search - A.A., O.Z.; Writing A.A., O.Z.; Critical Reviews - A.A., O.Z. 
Conflict of Interest: No conflict of interest was declared by the authors.

Financial Disclosure: The authors declared that this study has received no financial support.

\section{REFERENCES}

1. Jemal A, Siegel R, Xu J, Ward E. Cancer statistics, 2010. CA Cancer J Clin 2010;60:277-300. [CrossRef]

2. Early Breast Cancer Trialists' Collaborative Group. Effects of chemotherapy and hormonal therapy for early breast cancer on recurrence and 15-year survival: an overview of the randomised trials. Lancet 2005;365:1687-717.[CrossRef]

3. Burstein HJ,Harris JR, Morrow M. Malignant tumors of the breast. In: DeVita VT, Lawrence TS, Rosenberg SA, eds. DeVita, Hellman, and Rosenberg's Cancer Principles \& practice of oncology. 9th ed. Philadelphia: Lippincott Williams \& Wilkins; 2011.p.1401-46.

4. Adamczyk A1, Niemiec J, Ambicka A, Małecki K, Wysocki WH, Mituś $\mathrm{J}$, et al. Expression of ER/PR/HER2, basal markers and adhesion molecules in primary breast cancer and in lymph nodes metastases: a comparative immunohistochemical analysis. Pol J Pathol 2012;63:228-34.

5. Gown AM. Current issues in ER and HER2 testing by IHC in breast cancer. Mod Pathol 2008;21(Suppl 2):S8-15. [CrossRef]

6. Leake R, Barnes D, Pinder S, Ellis I, Anderson L, Anderson T, et al. Immunohistochemical detection of steroid receptors in breast cancer: a working protocol. UK Receptor Group, UK NEQAS, The Scottish Breast Cancer Pathology Group, and The Receptor and Biomarker Study Group of the EORTC. J Clin Pathol 2000;53:634-5.[CrossRef]

7. Rhodes A, Jasani B, Balaton AJ, Miller KD. Immunohistochemical demonstration of estrogen and progesterone receptors: correlation of standards achieved on in house tumours with that achieved on external quality assessment material in over 150 laboratories from 26 countries. J Clin Pathol 2000;53:292-301.[CrossRef]

8. Rhodes A, Jasani B, Balaton AJ, Barnes DM, Anderson E, Bobrow LG, et al. Study of interlaboratory reliability and reproducibility of estrogen and progesterone receptor assays in Europe: documentation of poor reliability and identification of insufficient microwave antigen retrieval time as a major contributory element of unreliable assays. Am J Clin Pathol 2001;115:44-58. [CrossRef]

9. Oyama T, Ishikawa Y, Hayashi M, Arihiro K, Horiguchi J. The effects of fixation, processing and evaluation criteria on immunohistochemical detection of hormone receptors in breast cancer. Breast Cancer 2007;14:182-8.[CrossRef]

10. Grizzle WE. Special symposium: Fixation and tissue processing models. Biotech Histochem 2009;84:185-93. [CrossRef]
11. Fitzgibbons PL, Murphy DA, Hammond ME, Allred DC, Valenstein PN. Recommendations for validating estrogen and progesterone receptor immunohistochemistry assays. Arch Pathol Lab Med 2010;134:930-5.

12. Goldstein NS, Ferkowicz M, Odish E, Mani A, Hastah F. Minimum formalin fixation time for consistent estrogen receptor immunohistochemical staining of invasive breast carcinoma. Am J Clin Pathol 2003;120:86-92. [CrossRef]

13. Apple S, Pucci R, Lowe AC, Shintaku I, Shapourifar-Tehrani S, Moatamed N. The effect of delay in fixation, different fixatives, and duration of fixation in estrogen and progesterone receptor results in breast carcinoma. Am J Clin Pathol 2011;135:592-8. [CrossRef]

14. Khoury T, Sait S, Hwang H, Chandrasekhar R, Wilding G, Tan D, et al. Delay to formalin fixation effect on breast biomarkers. Mod Pathol 2009;22:1457-67. [CrossRef]

15. De Marzo AM, Fedor HH, Gage WR, Rubin MA. Inadequate formalin fixation decreases reliability of p27 immunohistochemical staining: probing optimal fixation time using highdensity tissue microarrays. Hum Pathol 2002;33:756-60.[CrossRef]

16. Grizzle WE, Stockard CR, Billings PE. The effects of tissue processing variables other than fixation on histochemical staining and immunohistochemical detection of antigens. J Histotechnol 2001;24:213-9. [CrossRef]

17. Taylor CR, Shi SR. Antigen retrieval: call for a return to first principles. Appl Immunohistochem Mol Morphol 2000;8:173-4.[CrossRef]

18. Werner M, Chott A, Fabiano A, Battifora H. Effect of formalin tissue fixation and processing on immunohistochemistry. Am J Surg Pathol 2000;24:1016-9.[CrossRef]

19. Yamashita S, Okada Y. Application of heat-induced antigen retrieval to aldehyde-fixed fresh frozen sections. J Histochem Cytochem 2005;53:1421-32. [CrossRef]

20. Shi SR, Liu C, Pootrakul L, Tang L, Young A, Chen R, Cote RJ, et al. Evaluation of the value of frozen tissue section used as "gold standard" for immunohistochemistry. Am J Clin Pathol 2008;129:358-66. [CrossRef]

21. Eltoum I, Fredenburgh J, Myers RB, Grizzle WE. Introduction to the theory and practice of fixation of tissues. J Histotechnol 2001;24:173-90. [CrossRef]

22. Karimi-Busheri F, Zadorozhny V, Carrier E, Fakhrai H. Molecular integrity and global gene expression of breast and lung cancer stem cells under long-term storage and recovery. Cell Tissue Bank 2013;14:175-86. [CrossRef]

23. Caboux E, Paciencia M, Durand G, Robinot N, Wozniak MB, GalateauSalle F, et al. Impact of delay to cryopreservation on RNA integrity and genome-wide expression profiles in resected tumor samples. PLoS One 2013;8:e79826. [CrossRef] 